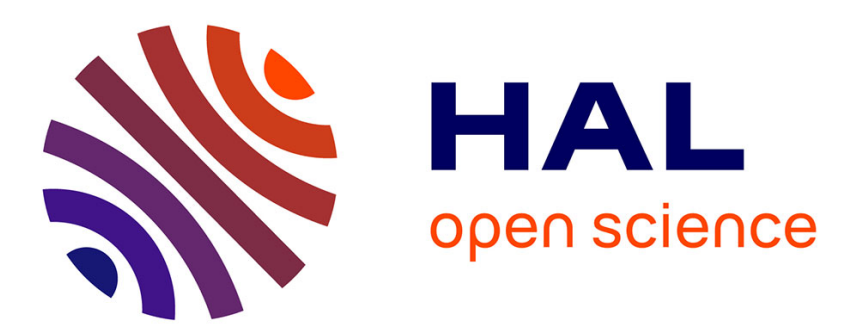

\title{
Incoherence detection and approximate solving of equations using fuzzy qualitative reasoning
}

Didier Dubois, Allel Hadj Ali, Henri Prade

\section{To cite this version:}

Didier Dubois, Allel Hadj Ali, Henri Prade. Incoherence detection and approximate solving of equations using fuzzy qualitative reasoning. 9th IEEE International Conference on Fuzzy Systems (FUZZIEEE 2000), May 2000, San Antonio (Texas), United States. pp.203-214. hal-03403391

\section{HAL Id: hal-03403391 \\ https://hal.science/hal-03403391}

Submitted on 27 Oct 2021

HAL is a multi-disciplinary open access archive for the deposit and dissemination of scientific research documents, whether they are published or not. The documents may come from teaching and research institutions in France or abroad, or from public or private research centers.
L'archive ouverte pluridisciplinaire HAL, est destinée au dépôt et à la diffusion de documents scientifiques de niveau recherche, publiés ou non, émanant des établissements d'enseignement et de recherche français ou étrangers, des laboratoires publics ou privés. 


\title{
Incoherence Detection and Approximate Solving of Equations Using Fuzzy Qualitative Reasoning
}

\author{
Didier DUBOIS* Allel HADJ-ALI** Henri PRADE* \\ *I.R.I.T, Universit Paul Sabatier \\ **Institut d Informatique \\ Universit Mouloud Mammeri \\ 31062 Toulouse Cedex 4, France \\ 15000 Tizi-ouzou, Algeria
}

\begin{abstract}
This paper deals with relative orders of magnitude reasoning that handles notions such as. closeness $(\mathrm{Cl})$ and negligibility $(\mathrm{Ne})$, by means of fuzzy relations $A$ set of inference rules describes how these relations can be composed and how they behave with respect to addition and product. Fuzzy numbers play the role of parameters underlying the semantics of $\mathrm{Cl}$ and Ne. Some of rules lead to conclusions involving Closeness relations which are not longer symmetric. We propose symmetric variants of these rules. The results provided by these variants are sound but not complete; although the symbolic reasoning is made easier. We show that this type of reasoning can be used for proving the incoherence of set of equations or finding approximate solutions thereof.
\end{abstract}

\section{INTRODUCTION}

Qualitative reasoning about physical systems has been an important research area in AI in the last decade [8][9]. The main aim of such reasoning is both to address the need to deal with physical systems where some magnitudes are not easy to quantify (numerical data are not available), and to be able to reason at a qualitative or symbolic level (for example, reasoning directly in terms of orders of magnitude). Significant progress towards the development of formal methods for qualitative reasoning about the behavior of physical systems has been made. The simplest formalism used in qualitative reasoning is based on the sign algebra $(-, 0,+)$; see for instance [8][9]. Such models are enough to represent the sign of quantities and the direction in which each quantity affects another quantity. Information about magnitudes, or even relative orders of magnitude is not represented. As a consequence, the signbased approach has too limited an expressive power in some practical cases to be widely applicable. A major limitation lies in the fact that often the sign of the result of an operation can be determined only if the order of magnitude of the involved parameters are considered. The only knowledge of the sign of the quantities involved in a mathematical expression often leaves the sign of the result completely indeterminate.

Reasoning with relative orders of magnitude is an attempt towards overcoming these limitations. See [9][11] for a general discussion. It corresponds to a particular form of commonsense reasoning where the ideas of closeness, comparability and negligibility are involved. The first attempt to formalize such reasoning appeared with the formal system FOG, proposed by Raiman [11]. FOG is based on three basic relations expressing the relations negligible in relation to $(\mathrm{Ne})$, close to $(\mathrm{Cl})$, and has the same sign and order of magnitude as, i.e., is comparable to (Co). FOG includes one axiom and 31 inference rules, which allow for deduction from pieces of knowledge expressed in terms of relative orders of magnitude. This set of rules was proved consistent in the semantic framework of Non-Standard Analysis. FOG handles relative orders of magnitude through a purely symbolic computation process. No numerical interpretation is provided for the symbolic computation of orders of magnitude. FOG thus does not allow for the incorporation of numerical values, nor does itt take into account the fact that the satisfaction of relations $\mathrm{Ne}, \mathrm{Cl}$ and $\mathrm{Co}$, by two numerical values is often a matter of degree. It does not cope with the fact that these relations are contextdependent. It has been pointed out in [3][4][5] that fuzzy relations are an appropriate framework for modeling relations $\mathrm{Ne}, \mathrm{Cl}$ and $\mathrm{Co}$. Moreover this new semantics can express that the relation $\mathrm{Cl}$ (resp. $\mathrm{Ne}$ ) is usually transitive in a weak (resp. strong) sense rather than just transitive.

A set of symbolic inference rules has been developed, based on fuzzy relations $\mathrm{Cl}$ and $\mathrm{Ne}$ [4][5]. Fuzzy numbers play the role of the parameters underlying the semantics of $\mathrm{Cl}$ and $\mathrm{Ne}$. They are manipulated at a symbolic level. These parameters are supposed to guarantee the symmetry of the closeness relations (since if $a$ is close to $b$ then $b$ is close to a). Unfortunately, some of rules lead to conclusions involving relations which are not longer symmetric. Therefore, the use of relations obtained by these rules, when the rules are applied in cascade, could lead to undesirable results. In order to overcome this drawback, we propose variants of these rules, namely weaker rules syntactically derivable from other already established rules, and preserving the symmetry of $\mathrm{Cl}$.

A set of closeness and negligibility relations stated between variables which are related by equations, are not necessarily coherent. Considering the restricted character of vocabulary, an incoherence can be only expressed under the form: There are two quantities $a$ and $b$ such that $a$ is negligible w.r.t. $b$ and $a$ is close to $b$ (or $b$ is 
negligible w.r.t. a ). An incoherence arises in a set of equations, if by application of rules such contradictory conclusions follow. Two examples will illustrate this situation.

The paper is organized as follows. Section 2 recalls the fuzzy representation of relations $\mathrm{Ne}$ and $\mathrm{Cl}$. In Section 3, we present a minimal set of inference rules describing the behavior of relations $\mathrm{Ne}$ and $\mathrm{Cl}$, and we discuss some required properties of the fuzzy parameters underlying the semantics of these relations. Symmetric variants of some rules, are proposed in section 4 . Lastly, Section 5 shows how symbolic reasoning based on the fuzzy relations $\mathrm{Cl}$ and $\mathrm{Ne}$ can be used for detecting the incoherence of a set of equations.

\section{REPRESENTATION OF RELATIVE ORDERS OF MAGNITUDE WITH FUZZY RELATIONS}

Relative orders of magnitude can be expressed by fuzzy relations whose membership functions are defined in terms of difference of values or in terms of ratio of values [4][5]. The ratio $x / y$, is more natural than the difference $x-y$, especially when modelling negligibility. An approximate equality relation, represented by closeness relation $\mathrm{Cl}$, can be captured by the following fuzzy relation between two real numbers $x$ and $y$ :

$$
\mathrm{Cl}_{\mathrm{Cl}}(\mathrm{x}, \mathrm{y})={ }_{\mathrm{M}}(\mathrm{x} / \mathrm{y})
$$

where the characteristic function $M$ is the one of a fuzzy number close to 1 , such that ${ }_{M}(1)=1$ (since $x$ is close to $\mathrm{x}),{ }_{M}(\mathrm{t})=0$ if $\mathrm{t} \leq 0$ (since two numbers which are close should have the same sign), and more generally such that

$$
M(t)=M(1 / t)
$$

This last property ensures the symmetry of $\mathrm{Cl}$, i.e.,

$$
\mathrm{Cl}(\mathrm{x}, \mathrm{y})=\mathrm{Cl}(\mathrm{y}, \mathrm{x})
$$

In the formal system FOG [11], the relation $\mathrm{Ne}$ can be expressed in terms of $\mathrm{Cl}$ through the following rule:

$$
(a, b) \in \mathrm{Ne} \Leftrightarrow(a+b, b) \in \mathrm{Cl},
$$

which leads to the following representation :

$$
\mathrm{Ne}(\mathrm{x}, \mathrm{y})={ }_{\mathrm{M}}((\mathrm{x}+\mathrm{y}) / \mathrm{y})={ }_{\mathrm{M}}(1+\mathrm{x} / \mathrm{y})
$$

. In the system FOG, Raiman mentions a third relation of comparability Co definable in terms of $\mathrm{Ne}[(\mathrm{a}, \mathrm{b}) \in \mathrm{Co} \Leftrightarrow$ $\neg((a, b) \in \mathrm{Ne}$ or $(b, a) \in \mathrm{Ne}))]$. We shall not use this less elementary relations in the following.

From now on, the notation $\mathrm{Cl}[\mathrm{M}]$ (resp. $\mathrm{Ne}[\mathrm{M}]$ ) signifies that $\mathrm{Cl}$ (resp. $\mathrm{Ne}$ ) is defined from the membership function (1) (resp. (4)). We shall continue to use the notation (a,b) $\in \mathrm{Cl}[\mathrm{M}]$ and $(\mathrm{a}, \mathrm{b}) \in \mathrm{Ne}[\mathrm{M}]$ for expressing that the more or less possible pairs of values for $a$ and $b$ are restricted by the fuzzy sets $\mathrm{Cl}[\mathrm{M}]$ and $\mathrm{Ne}[\mathrm{M}]$ respectively.
The representation of relations in terms of ratios enables to reduce the composition of fuzzy relations (as done in the approximate reasoning [12]) to a simple computation on the fuzzy numbers which parameterize the relations. Indeed $\operatorname{Sup}_{\mathrm{y}} \min \left(\mathrm{Cl}_{[\mathrm{M}]}(\mathrm{x}, \mathrm{y}), \mathrm{Cl}_{\mathrm{N}]}(\mathrm{y}, \mathrm{z})\right)=$

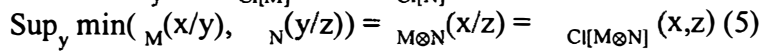

Where $\otimes$ denotes the product extended to fuzzy numbers (in the following, we shall omit $\otimes$ when writing products). Similarly, $\sup _{y} \min \left({ }_{\mathrm{Cl}[\mathrm{M}]}(\mathrm{x}, \mathrm{y}), \operatorname{Ne}_{\mathrm{N}] \mathrm{N}]}(\mathrm{y}, \mathrm{z})\right)=$ $\sup _{\mathrm{y}} \min \left({ }_{M}(\mathrm{x} / \mathrm{y}),{ }_{N}(1+\mathrm{y} / \mathrm{z})\right)=\sup _{\mathrm{u}, \mathrm{V}} \min \left({ }_{\mathrm{M}}(\mathrm{u}),{ }_{N}(\mathrm{v})\right)$, $\left.={ }_{M}(\mathrm{~N} \Theta 1)-1(1+\mathrm{x} / \mathrm{z})=\mathrm{Ne}_{\mathrm{N}} \mathrm{M}(\mathrm{N} \Theta \mathrm{I})-1\right](\mathrm{x}, \mathrm{z})$

letting $u=x / y$ and $v=1+y / z u(v-1)+1=1+x / z$, where $\oplus$ and $\Theta$ denote the addition and subtraction extended to fuzzy numbers [2]. Note that the expressions (5) and (6) lead to the following inference rules:

$(\mathrm{a}, \mathrm{b}) \in \mathrm{Cl}[\mathrm{M}]$ and $(\mathrm{b}, \mathrm{c}) \in \mathrm{Cl}[\mathrm{N}] \Rightarrow(\mathrm{a}, \mathrm{c}) \in \mathrm{Cl}[\mathrm{MN}]$ $(a, b) \in \mathrm{Cl}[\mathrm{M}]$ and $(b, c) \in \mathrm{Ne}[\mathrm{N}] \Rightarrow(\mathrm{a}, \mathrm{c}) \in \mathrm{Ne}[\mathrm{M}(\mathrm{N} \Theta 1) \oplus 1]$

\section{INFERENCE RULES BASED ON FUZZY RELATIONS NE AND CL}

\section{A. A Set of Inference Rules}

A set of symbolic inference rules, based on the order of magnitude relations $\mathrm{Cl}$ and $\mathrm{Ne}$, has been proposed and justified in [4] and [5]. Nevertheless, these are not independent. For example, it is easy to see that the rules : $(\mathrm{a}, \mathrm{b}) \in \mathrm{Ne}[\mathrm{M}] \Leftrightarrow(\mathrm{a}+\mathrm{b}, \mathrm{b}) \in \mathrm{Cl}[\mathrm{M}]^{\circ}$ and $(\mathrm{a}, \mathrm{b}) \in \mathrm{Cl}[\mathrm{M}]$ and $(\mathrm{b}, \mathrm{c}) \in \mathrm{Cl}[\mathrm{N}] \Rightarrow(\mathrm{a}, \mathrm{c}) \in \mathrm{Cl}[\mathrm{MN}]$ imply the rule

$(a, c) \in \mathrm{Cl}[\mathrm{M}]$ and $(b, a) \in \mathrm{Ne}[\mathrm{N}] \Rightarrow(\mathrm{a}+\mathrm{b}, \mathrm{c}) \in \mathrm{Cl}[\mathrm{MN}]$, or that $(a, b) \in \mathrm{Ne}[\mathrm{M}] \Leftrightarrow(-\mathrm{a}, \mathrm{b}) \in \mathrm{Ne}[2 \Theta \mathrm{M}]^{\circ}$

and $(a, b) \in \mathrm{Ne}[\mathrm{M}] \Leftrightarrow(a+b, b) \in \mathrm{Cl}[\mathrm{M}]$

imply the rule $(a-b, a) \in \mathrm{Ne}[\mathrm{M}] \Leftrightarrow(b, a) \in \mathrm{Cl}[2 \Theta \mathrm{M}]$.

Furthermore, some rules can be redundant $A$ rule is redundant with respect to another, if under the same conditions, it leads to a conclusion containing (inclusion of fuzzy sets) the one of the other rule. A minimal set of rules (independent) can be obtained by performing the following operations [7]:

i) Deleting all rules which can be obtained by chaining of two or several rules;

ii) Eliminating all rules, which by renaming variables, coincide with others (for example, the rule: $(a, b) \in \mathrm{Ne}[\mathrm{M}]$ $\Leftrightarrow(a+b, b) \in C l[M])$, letting $a=c-b$, yields: $(c-b, b) \in N e[M]$ $\Leftrightarrow(\mathrm{c}, \mathrm{b}) \in \mathrm{Cl}[\mathrm{M}])$, another rule given in [5].

The application of these two operations leads to the following rule base

Remarkable properties of $\mathrm{Cl}$ $\mathrm{a} \leq \mathrm{b}$ and $\mathrm{c} \leq \mathrm{d}$ and $\mathrm{a} / \mathrm{b} \leq \mathrm{c} / \mathrm{d}$ and $(\mathrm{a}, \mathrm{b}) \in \mathrm{Cl}[\mathrm{M}] \Rightarrow$ $(\mathrm{c}, \mathrm{d}) \in \mathrm{Cl}[\mathrm{M}]$ $(a, b) \in \mathrm{Cl}[\mathrm{M}] \Leftrightarrow(\mathrm{b}, \mathrm{a}) \in \mathrm{Cl}[\mathrm{M}]$

$(\mathrm{a}, \mathrm{b}) \in \mathrm{Cl}[\mathrm{M}]$ et $(\mathrm{c}, \mathrm{d}) \in \mathrm{Cl}[\mathrm{N}] \Rightarrow(\mathrm{a} \cdot \mathrm{c}, \mathrm{b} \cdot \mathrm{d}) \in \mathrm{Cl}[\mathrm{MN}]$ 
Definition of $\mathrm{Ne}$ from $\mathrm{Cl}$

$(a, b) \in \mathrm{Ne}[\mathrm{M}] \Leftrightarrow(a+b, b) \in \mathrm{Cl}[\mathrm{M}]$

$(a, b) \in \operatorname{Cl}[M] \Leftrightarrow(\max (a, b)-\min (a, b), \min (a, b)) \in \operatorname{Ne}[M]$

$(\mathrm{a}, \mathrm{b}) \in \mathrm{Ne}[\mathrm{M}] \Leftrightarrow(-\mathrm{a}, \mathrm{b}) \in \mathrm{Ne}[2 \Theta \mathrm{M}]$

Remarkable properties of $\mathrm{Ne}$

if $\mathrm{a} \leq \mathrm{b}$ and $(\mathrm{b}, \mathrm{c}) \in \mathrm{Ne}[\mathrm{M}] \Rightarrow(\mathrm{a}, \mathrm{c}) \in \mathrm{Ne}[\mathrm{M}]$

if $(a, b) \in \mathrm{Ne}[\mathrm{M}]$ and $b \leq c \Rightarrow(a, c) \in \mathrm{Ne}[\mathrm{M}]$

$(\mathrm{a}, \mathrm{a}+\mathrm{b}) \in \mathrm{Ne}[\mathrm{M}] \Rightarrow(\mathrm{a}, \mathrm{b}) \in \mathrm{Ne}[2 \Theta \mathrm{M}]$

$(a, b) \in \mathrm{Ne}[\mathrm{M}]$ and $(\mathrm{c}, \mathrm{d}) \in \mathrm{Ne}[\mathrm{N}] \Rightarrow$

$(\mathrm{a} \cdot \mathrm{c}, \mathrm{b} \cdot \mathrm{d}) \in \mathrm{Ne}[(\mathrm{M} \Theta 1)(\mathrm{N} \Theta 1) \oplus 1]$

Composition of relations $\mathrm{Cl}$ and $\mathrm{Ne}$

$(\mathrm{a}, \mathrm{b}) \in \mathrm{Cl}[\mathrm{M}]$ and $(\mathrm{b}, \mathrm{c}) \in \mathrm{Ne}[\mathrm{N}] \Rightarrow(\mathrm{a}, \mathrm{c}) \in \mathrm{Ne}[\mathrm{M}(\mathrm{N} \Theta 1) \oplus 1]$

$(a, b) \in \mathrm{Cl}[\mathrm{M}]$ and $(\mathrm{c}, \mathrm{a}) \in \mathrm{Ne}[\mathrm{N}] \Rightarrow(\mathrm{c}, \mathrm{b}) \in \mathrm{Ne}[\mathrm{M}(\mathrm{N} \Theta 1) \oplus 1]$

Properties of $\mathrm{Cl}$ and $\mathrm{Ne}$ with respect to the addition

$(\mathrm{a}, \mathrm{c}) \in \mathrm{Cl}[\mathrm{M}] \quad$ and $\quad(\mathrm{b}, \mathrm{c}) \in \mathrm{Ne}[\mathrm{N}] \quad \Rightarrow$

$(\mathrm{a}+\mathrm{b}, \mathrm{c}) \in \mathrm{Cl}[\mathrm{M} \oplus \mathrm{N} \Theta 1](19)$

$(\mathrm{a}+\mathrm{b}, \mathrm{c}) \in \mathrm{Cl}[\mathrm{M}]$ and $(\mathrm{b}, \mathrm{c}) \in \mathrm{Cl}[\mathrm{N}]$ $\Rightarrow(\mathrm{a}, \mathrm{c}) \in \mathrm{Ne}[\mathrm{M} \Theta \mathrm{N} \oplus 1]$

$(\mathrm{a}, \mathrm{c}) \in \mathrm{Ne}[\mathrm{M}]$ and $(\mathrm{b}, \mathrm{a}) \in \mathrm{Ne}[\mathrm{N}]$

$$
\Rightarrow(\mathrm{a}+\mathrm{b}, \mathrm{c}) \in \mathrm{Ne}[(\mathrm{M} \Theta 1) \mathrm{N} \oplus 1]
$$

Properties of $\mathrm{Cl}$ and $\mathrm{Ne}$ with respect to the product

$(\mathrm{a}, \mathrm{b}) \in \mathrm{Cl}[\mathrm{M}]$ and $(\mathrm{c}, \mathrm{d}) \in \mathrm{Ne}[\mathrm{N}]$

$$
\Rightarrow(\mathrm{a} \cdot \mathrm{c}, \mathrm{b} \cdot \mathrm{d}) \in \mathrm{Ne}[\mathrm{M}(\mathrm{N} \Theta 1) \oplus 1]
$$

From this set of inference rules, other useful simplifying rules can be derived:

If $c \neq 0,(a \cdot c, b \cdot c) \in \mathrm{Ne}[\mathrm{M}] \Leftrightarrow(a, b) \in \mathrm{Ne}[\mathrm{M}]$

If $c \neq 0,(a \cdot c, b \cdot c) \in \mathrm{Cl}[\mathrm{M}] \Leftrightarrow(a, b) \in \mathrm{Cl}[\mathrm{M}]$

$(a, b) \in \mathrm{Cl}[\mathrm{M}]$ and $(b, c) \in \mathrm{Cl}[\mathrm{N}] \Rightarrow(\mathrm{a}, \mathrm{c}) \in \mathrm{Cl}[\mathrm{MN}]$

$(a, b) \in \mathrm{Ne}[\mathrm{M}]$ and $(b, c) \in \mathrm{Ne}[\mathrm{N}] \Rightarrow$

$(\mathrm{a}, \mathrm{c}) \in \mathrm{Ne}[(\mathrm{M} \Theta 1)(\mathrm{N} \Theta 1) \oplus 1]$

$(\mathrm{a}+\mathrm{b}, \mathrm{c}) \in \mathrm{Cl}[\mathrm{M}] \&(\mathrm{~b}, \mathrm{a}) \in \mathrm{Ne}[\mathrm{N}] \Rightarrow(\mathrm{a}, \mathrm{c}) \in \mathrm{Cl}[\mathrm{MN}]$

$(\mathrm{a} \cdot \mathrm{b}, \mathrm{c} \cdot \mathrm{d}) \in \mathrm{Cl}[\mathrm{M}] \&(\mathrm{a}, \mathrm{c}) \in \mathrm{Cl}[\mathrm{N}] \Rightarrow(\mathrm{b}, \mathrm{d}) \in \mathrm{Cl}[\mathrm{MN}]$

$(28)(a \cdot b, c \cdot d) \in \mathrm{Ne}[\mathrm{M}]$ and $(\mathrm{c}, \mathrm{a}) \in \mathrm{Ne}[\mathrm{N}]$ $\Rightarrow(\mathrm{b}, \mathrm{d}) \in \mathrm{Cl}[(\mathrm{M} \Theta \mathrm{l})(\mathrm{N} \Theta \mathrm{l}) \oplus 1]$

$(\mathrm{a}+\mathrm{b}, \mathrm{c}) \in \mathrm{Cl}[\mathrm{M}]$ and $(\mathrm{b}, \mathrm{c}) \in \mathrm{Ne}[\mathrm{N}] \Rightarrow$

$(\mathrm{a}, \mathrm{c}) \in \mathrm{Cl}[\mathrm{M} \Theta \mathrm{N} \oplus 1]$

$(a+b, c) \in \mathrm{Ne}[\mathrm{M}]$ and $(b, c) \in \mathrm{Ne}[\mathrm{N}]$

$$
\Rightarrow(\mathrm{a}, \mathrm{c}) \in \mathrm{Ne}[\mathrm{M} \Theta \mathrm{N} \oplus 1]
$$

$(a, c) \in \mathrm{Ne}[\mathrm{M}]$ and $(\mathrm{b}, \mathrm{c}) \in \mathrm{Ne}[\mathrm{N}]$ $\Rightarrow(\mathrm{a}+\mathrm{b}, \mathrm{c}) \in \mathrm{Ne}[\mathrm{M} \oplus \mathrm{N} \oplus 1]$

$(\mathrm{a}-\mathrm{b}, \mathrm{c}) \in \mathrm{Cl}[\mathrm{M}]$ and $(\mathrm{a}, \mathrm{c}) \in \mathrm{Cl}[\mathrm{N}] \Rightarrow$

$(b, c) \in \mathrm{Ne}[\mathrm{N} \Theta \mathrm{M} \oplus 1]$

$(a-b, c) \in \mathrm{Ne}[\mathrm{M}]$ and $(a, c) \in \mathrm{Cl}[\mathrm{N}]$ $\Rightarrow(b, c) \in \mathrm{Cl}[\mathrm{N} \Theta \mathrm{M} \oplus 1]$

$(a \cdot b, c \cdot d) \in \mathrm{Cl}[\mathrm{M}]$ and $(a, c) \in \mathrm{Ne}[\mathrm{N}]$ $\Rightarrow(\mathrm{d}, \mathrm{b}) \in \mathrm{Ne}[\mathrm{M}(\mathrm{N} \Theta 1) \oplus 1]$

$(a \cdot b, c \cdot d) \in \mathrm{Ne}[\mathrm{M}]$ and $(\mathrm{c}, \mathrm{a}) \in \mathrm{Cl}[\mathrm{N}]$

$$
\Rightarrow(b, d) \in \mathrm{Ne}[(\mathrm{M} \Theta 1) \mathrm{N} \oplus 1]
$$

Proof: We only give the proof of one of these rules, as an example. Rule (26) is a consequence of rule (16) for $A=a, B=C=b$ and $D=c$, using (23). $n$

Nevertheless, in practice in order to build up an efficient symbolic reasoning system, it may be interesting to explicitly use simplifying rules even if they are redundant.

\section{B. Required Properties of the Fuzzy Parameter}

In equations (1) and (4), $M$ is a fuzzy number which restricts values around 1 such that $M(1)=1$. Moreover $M$ should verify the following constraints:

i) $\forall \mathrm{t}, \quad{ }_{M}(t)={ }_{M}(1 / t)$, i.e. $M$ satisfies the symmetry property, ensuring the symmetry of relation $\mathrm{Cl}$. Then, a level cut of $M$ is of the form $[1-\varepsilon, 1 /(1-\varepsilon)]$ with $\varepsilon \in[0,1[$.

ii) ${ }_{N e[M]}(x, y)=0$ for $x=y$ (since $x$ is not negligible with relation to itself), this is equivalent (according to (4)) to $M(2)=0$. Since $M$ is symmetric, we also have ${ }_{M}(1 / 2)=$ 0 . If $\left[m_{1}, m_{2}\right]$ is the support of $M\left(\right.$ with $m_{1}=1 / m_{2}$ ) then $\left[\mathrm{m}_{1}, \mathrm{~m}_{2}\right]$ is included in $[1 / 2,2]$.

iii) The support of the fuzzy number $2 \Theta \mathrm{M}$ is included in the positive real axis, since the support of $M$ is in $[0,2]$. A level cut of $2 \Theta \mathrm{M}$ is of the form $[(1-2 \varepsilon) /(1-\varepsilon), 1+\varepsilon]$. The number $2 \Theta M$ is symmetric if $(1-2 \varepsilon) /(1-\varepsilon)=1 /(1+\varepsilon)$. Only $(1-2 \varepsilon) /(1-\varepsilon) \cong 1 /(1+\varepsilon)$ holds, neglecting $\varepsilon^{2}$. In order to approximate $2 \Theta \mathrm{M}$ by its symmetric part $[1 /(1+\varepsilon), 1+\varepsilon]$, the relation $(1-2 \varepsilon) /(1-\varepsilon) \geq 1 / 2$ is supposed to hold (since $(1-2 \varepsilon) /(1-\varepsilon) \leq 1 /(1+\varepsilon)$ and $1 /(1+\varepsilon) \geq 1 / 2)$; which implies that $\varepsilon \leq 1 / 3$ (i.e. $\varepsilon \in[0,1 / 3]$ ).

Thus, the support of the fuzzy number $M,\left[m_{1}, m_{2}\right]$, should included in the interval [2/3,3/2]. Each level cut of $M$ is of the form $[1-\varepsilon, 1 /(1-\varepsilon)]$ with $\varepsilon \in[0,1 / 3]$.

\section{SYMMETRIC VARIANTS OF RULES}

Some of the semantically justified inference rules, are not valid at the syntactic level; since the parameters underlying the relations appearing in the conclusions parts, are not symmetric. This fact might creates some problems when reasoning symbolically with these rules. For instance, we cannot use rule (8) if the parameter of $\mathrm{Cl}$ is not symmetric. It can lead to undesirable results.

In the following, we propose variants of rules (16) to (22); namely weaker rules which are syntactically derivable from others, and whose parameters underlying the relations (in conclusion parts) do verify the property of symmetry:

$(a, b) \in \mathrm{Ne}[\mathrm{M}]$ and $(\mathrm{c}, \mathrm{d}) \in \mathrm{Ne}[\mathrm{N}] \Rightarrow(\mathrm{a} \cdot \mathrm{c}, \mathrm{b} \cdot \mathrm{d}) \in \mathrm{Ne}[\mathrm{MN}](37)$

$(a, b) \in \mathrm{Cl}[\mathrm{M}]$ and $(\mathrm{b}, \mathrm{c}) \in \mathrm{Ne}[\mathrm{N}] \Rightarrow(\mathrm{a}, \mathrm{c}) \in \mathrm{Ne}[\mathrm{MN}]$

$(\mathrm{a}, \mathrm{b}) \in \mathrm{Cl}[\mathrm{M}]$ and $(\mathrm{c}, \mathrm{a}) \in \mathrm{Ne}[\mathrm{N}] \Rightarrow(\mathrm{c}, \mathrm{b}) \in \mathrm{Ne}[\mathrm{MN}]$

$(\mathrm{a}, \mathrm{c}) \in \mathrm{Cl}[\mathrm{M}]$ and $(\mathrm{b}, \mathrm{c}) \in \mathrm{Ne}[\mathrm{N}] \Rightarrow(\mathrm{a}+\mathrm{b}, \mathrm{c}) \in \mathrm{Cl}[\mathrm{MN}] \quad$ (40)

$(\mathrm{a}+\mathrm{b}, \mathrm{c}) \in \mathrm{Cl}[\mathrm{M}]$ and $(\mathrm{b}, \mathrm{c}) \in \mathrm{Cl}[\mathrm{N}] \Rightarrow(\mathrm{a}, \mathrm{c}) \in \mathrm{Ne}[\mathrm{MN}]$

$(a, c) \in \mathrm{Ne}[\mathrm{M}]$ and $(b, a) \in \mathrm{Ne}[\mathrm{N}] \Rightarrow(\mathrm{a}+\mathrm{b}, \mathrm{c}) \in \mathrm{Ne}[\mathrm{MN}](42)$

$(\mathrm{a}, \mathrm{b}) \in \mathrm{Cl}[\mathrm{M}]$ and $(\mathrm{c}, \mathrm{d}) \in \mathrm{Ne}[\mathrm{N}] \Rightarrow(\mathrm{a} \cdot \mathrm{c}, \mathrm{b} \cdot \mathrm{d}) \in \mathrm{Ne}[\mathrm{MN}]$ (43) 
Proof: For lack of space, we only prove Rule (37): By applying rule (10), we obtain $(a+b, b) \in \mathrm{Cl}[\mathrm{M}]$ and $(c+d$, d) $\in \mathrm{Cl}[\mathrm{N}]$. The rule (9) enables to deduce that $((a+b) \cdot(c+d), b \cdot d) \in C l[M N]$, which implies that $(a \cdot c+a \cdot d+b \cdot d+b \cdot c, b \cdot d) \in C l[M N]$. The rule (10) enables to obtain $(a \cdot c+a \cdot d+b \cdot c, b \cdot d) \in N e[M N]$. Since $a \cdot c \leq$ $a \cdot c+a \cdot d+b \cdot c$ (we suppose that $a, b, c$ et $d$ have the same sign), we conclude that $(\mathrm{a} \cdot \mathrm{c}, \mathrm{b} \cdot \mathrm{d}) \in \mathrm{Ne}[\mathrm{MN}]$ according to the rule (13).

$\mathrm{n}$

Note that rules (16) to (22) are optimal, since they are obtained using the combination/projection principle [12]. Therefore, the relations inferred, by the variants (37) to (43), are less restrictive. In other terms, the following inclusions are verified.: $(\mathrm{M} \Theta 1)(\mathrm{N} \Theta 1) \oplus 1 \subseteq \mathrm{MN}$ $\mathrm{M}(\mathrm{N} \Theta 1) \oplus 1 \subseteq \mathrm{MN}(45) ; \quad(\mathrm{M} \Theta 1) \mathrm{N} \oplus 1 \subseteq \mathrm{MN}$

Proof: For simplicity, we consider the case where $M=N$ Thus, the relations (44) to (46) write: $(\mathrm{M} \Theta 1)(\mathrm{M} \Theta 1) \oplus 1 \subseteq$ $\mathrm{M}^{2}$ (47); $\mathrm{M}(\mathrm{M} \Theta 1) \oplus 1 \subseteq \mathrm{M}^{2}$ (48); $(\mathrm{M} \Theta 1) \mathrm{M} \oplus 1 \subseteq \mathrm{M}^{2}$ (49). We use level cuts for verifying relations (47) to (49):

(47): The level cuts of $(\mathrm{M} \Theta 1)(\mathrm{M} \Theta 1) \oplus 1$ and $\mathrm{M}^{2}$ are [1$\left.\varepsilon^{2} /(1-\varepsilon), 1+\varepsilon^{2} /(1-\varepsilon)^{2}\right]$ and $\left[(1-\varepsilon)^{2}, 1 /(1-\varepsilon)^{2}\right]$ with $\varepsilon \in[0$, $1 / 3$, respectively. It is easy to see that $(1-\varepsilon)^{2} \leq 1-\varepsilon^{2} /(1-\varepsilon)$ and $1 /(1-\varepsilon)^{2} \geq 1+\varepsilon^{2} /(1-\varepsilon)^{2}, \forall \varepsilon \in[0,1 / 3]$.

(48): The level cut of $\mathrm{M}(\mathrm{M} \Theta 1) \oplus 1$ is of the form $[1-\varepsilon /(1-$ $\left.\varepsilon), 1+\varepsilon /(1-\varepsilon)^{2}\right]$. The inequalities $(1-\varepsilon)^{2} \leq 1-\varepsilon /(1-\varepsilon)$ and $1 /(1-$ $\varepsilon)^{2} \geq 1+\varepsilon /(1-\varepsilon)^{2}$ are verified, $\forall \varepsilon \in[0,1 / 3]$. It means that $\left[1-\varepsilon /(1-\varepsilon), 1+\varepsilon /(1-\varepsilon)^{2}\right] \subseteq\left[(1-\varepsilon)^{2}, 1 /(1-\varepsilon)^{2}\right]$. Thus, $(48)$ is verified.

- (49) holds since $(M \Theta 1) M \oplus 1=M(M \Theta 1) \oplus 1 \subseteq M^{2}$. n

It should be noted that the inclusion $M \oplus N \Theta 1 \subseteq M N$ (resp. $\mathrm{M} \Theta N \oplus 1 \subseteq \mathrm{MN}$ ), suggested by (40) (resp. (41)) seen as an approximation of (19) (resp. (20)), does not hold. Indeed a level cut of $M \oplus M \Theta 1$ (resp. $M \Theta M \oplus 1$ ) and $M M$ are of the form $\left[1-2 \varepsilon,\left(1-\varepsilon^{2}\right) /(1-\varepsilon)^{2}\right]$ (resp. $[1+\varepsilon(\varepsilon-2) /(1-\varepsilon)$, $\varepsilon+1 /(1-\varepsilon)])$ and $\left[(1-\varepsilon)^{2}, 1 /(1-\varepsilon)^{2}\right]$ respectively. We can easily verify that $1 /(1-\varepsilon)^{2} \geq\left(1-\varepsilon^{2}\right) /(1-\varepsilon)^{2}$ (resp. $1 /(1-\varepsilon)^{2} \geq$ $\varepsilon+1 /(1-\varepsilon)$ ), but we have $(1-\varepsilon)^{2} \geq 1-2 \varepsilon$ (resp. $(1-\varepsilon)^{2} \geq 1+\varepsilon(\varepsilon-$ $2) /(1-\varepsilon)$ ) for $\varepsilon \in[0,1 / 3]$. This situation is explained by the fact that rule (40) (resp. (41)) only holds in particular case where the quantities related in the condition and conclusion parts, have the same sign; and that in this particular case, Rule (19) (resp. (20)) will not provide the optimal restriction; since at the time of the projection we must add the constraint expressing that the quantities have the same sign (which implies that the quantity $1+u / v \geq 0$, $\forall \mathrm{u}, \mathrm{v})$.

The fuzzy parameters underlying the relations appearing in conclusions parts of the variants (37) to (43), are expressed under the form of the product of the fuzzy parameters (which are symmetric) underlying the relations involved in the conditions parts. So, these parameters will verify the property of symmetry (since the operation of product preserves this property). This enables us to use all the rules base without restriction or caution and make chaining on the inference rules without arbitrary limitations.

Unfortunately, the results provided by the variants (37) to (43), can be sometimes too much imprecise if we want to preserve the semantics of the closeness and negligibility of the symbolically computed relations. Indeed the semantics property required in Section 3.2 for the support of $M$ (i.e. support of $M$ is included in [2/3, 3/2]), is not automatically preserved for the product operation. The closeness relations must be sufficiently exacting and restrictive so that the product of their parameters remains in the desirable interval (i.e. [2/3, 3/2]). More generally, we can compute which level cuts of the fuzzy number obtained as a symbolic parameter of a result, remain included in the interval $[2 / 3,3 / 2]$; this will provide a level of validity to this result.

Moreover, the approximation of the rule (16) by the symmetric variant (37), leads to a deterioration of the property of strong transitivity of the negligibility relation. Indeed, the rule (26) consequence of the rules (16) and (23), expresses that the relation $\mathrm{Ne}$ is strongly transitive (i.e. a is more negligible w.r.t. c than a w.r.t. b or b w.r.t. c, indeed $\mathrm{Ne}[\mathrm{M}] \supseteq \mathrm{Ne}[(\mathrm{M} \Theta 1)(\mathrm{N} \Theta 1) \oplus 1])$; this property is not preserved by the variant of (26) obtained by chaining the rules (37) and (23) (since $\mathrm{Ne}[\mathrm{M}] \subseteq \mathrm{Ne}[\mathrm{MN}]$ ). A best symmetric approximation of (16) is provided taking as conclusion $(\mathrm{a}, \mathrm{c}) \in \mathrm{Ne}[\mathrm{M}]$ (resp. $\mathrm{Ne}[\mathrm{N}])$ if we have the inclusion of the fuzzy sets $M \supseteq N$ (resp. $N \supseteq M$ ).

\section{DETECTING THE INCOHERENCE OF A SET OF EQUATIONS}

In this section, we show how a set of equations composed of arithmetic expressions, can be simplified using the symbolic reasoning based on the relations $\mathrm{Ne}$ and $\mathrm{Cl}$, if such relations are known between the variables. $\dot{W e}$ show that we can also establish the incoherence of a such of set of equations and relations, by reductio ad absurdum.

\section{A. Coherence of Fuzzy Knowledge Bases}

In the possibilistic framework, each piece of knowledge is represented by a possibility distribution (d.p) $\pi_{i}$. A d.p expresses a (fuzzy) restriction on the possible values of a tuple of variables.

Definition 1: A set of d.p. forming a base $K$ is said to be incoherent if and only if 


$$
\forall \underline{x}=\left(x_{1}, K, x_{n}\right) \in X=X_{1} \times K \times X_{n}, \min _{i=1, n} \pi_{i}^{e}(\underline{x})<1 .
$$

This incoherence is said to be strong if $\min _{\mathrm{i}=1, n} \pi_{\mathrm{i}}^{\mathrm{e}}(\underline{\mathrm{x}})=0$. If this degree is $1, \mathrm{~K}$ is coherent.

For more details about the coherence of fuzzy knowledge bases particularly the coherence of the fuzzy rules where the set of variables is supposed to be partitioned into input variables and non-input variables, the reader can consult[6].

\section{B. Incoherence of a Set of Equations}

Proposition: Let $x$ and $y$ be two real quantities. If the support of $M$ is included in [1- $\varepsilon, 1 /(1-\varepsilon)]$ with $\varepsilon \in[0,1 / 3]$, then $(x, y) \in \mathrm{Cl}[\mathrm{M}]$ if and only if $(\mathrm{x}, \mathrm{y}) \notin \mathrm{Ne}[\mathrm{M}]$.

Proof: (we continue to use the level cuts of $\mathrm{M}$ )

$(\mathrm{x}, \mathrm{y}) \in \mathrm{Cl}[\mathrm{M}] \Rightarrow 1-\varepsilon \leq \mathrm{x} / \mathrm{y} \leq 1 /(1-\varepsilon), \forall \varepsilon \in[0,1 / 3] \Rightarrow$ $1+(1-\varepsilon) \leq 1+x / y \leq 1+1 /(1-\varepsilon) \Rightarrow 2-\varepsilon \leq 1+x / y \leq 1+1 /(1-\varepsilon)$

Now, we show that $2-\varepsilon>1 /(1-\varepsilon)$. This is equivalent to $\varepsilon^{2}-$ $3 \varepsilon+1>0$. This inequality is totally satisfied for $\varepsilon \in[0$, $1 / 3]$. Thus, $1+x / y \notin[1-\varepsilon, 1 /(1-\varepsilon)]$, hence $(x+y, y) \notin C l[M]$ which implies that $(\mathrm{x}, \mathrm{y}) \notin \mathrm{Ne}[\mathrm{M}]$. $\mathrm{n}$

Corollary: If in a system of equations, the following relations hold: $(\mathrm{x}, \mathrm{y}) \in \mathrm{Cl}[\mathrm{M}]$ and the support of $\mathrm{M}$ is included in $[1-\varepsilon, 1 /(1-\varepsilon)]$ with $\varepsilon \in[0,1 / 3]$, or $(x, y) \in$ $\mathrm{Ne}[\mathrm{M}]$ and the support of $\mathrm{M}$ is included in $[1-\eta, 1 /(1-\eta)]$ with $\eta \in[0,1 / 3]$, then the system is incoherent.

Proof: $(\mathrm{x}, \mathrm{y}) \in \mathrm{Cl}[\mathrm{M}] \Rightarrow 1-\varepsilon \leq \mathrm{x} / \mathrm{y} \leq 1 /(1-\varepsilon)$ with $\varepsilon \in[0$, $1 / 3],(x, y) \in \mathrm{Ne}[\mathrm{M}] \Rightarrow 1-\eta \leq 1+\mathrm{x} / \mathrm{y} \leq 1 /(1-\eta)$ with $\eta \in[0$, $1 / 3] \Rightarrow-\eta \leq x / y \leq 1 /(1-\eta)-1=\eta /(1-\eta)$.

Now, we show that $\eta /(1-\eta)<1-\varepsilon$. Since $\varepsilon \in[0,1 / 3]$, it suffices to check that $\eta /(1-\eta)<2 / 3$, which is verified for $\eta$ $\in[0,1 / 3]$. Which implies that $\eta /(1-\eta)<1-\varepsilon$. Which in turn enables to conclude that $\mathrm{x} / \mathrm{y} \notin[1-\varepsilon, 1 /(1-\varepsilon)]$ and therefore $(\mathrm{x}, \mathrm{y}) \notin \mathrm{Cl}[\mathrm{M}]$. Thus, there is a contradiction with the assumption that $(\mathrm{x}, \mathrm{y}) \in \mathrm{Cl}[\mathrm{M}]$.

$\mathrm{n}$

\section{Examples}

Example 1: Let us consider the following system :

$$
\begin{gathered}
(\mathrm{a} / \mathrm{b}+\mathrm{b} / \mathrm{c}, 1) \in \mathrm{Cl}[\mathrm{M}] \\
(\mathrm{a}, \mathrm{b}) \in \mathrm{Ne}[\mathrm{M}] \\
(\mathrm{b} \mathrm{c}) \in \mathrm{Ne}[\mathrm{M}]
\end{gathered}
$$

Is the system incoherent? Multiplying (50) by b, we get

$$
\left(a+b^{2} / c, b\right) \in \mathrm{Cl}[\mathrm{M}]
$$

Rule (12) applied on (51), implies that $(-a, b) \in$ $\mathrm{Ne}[2 \Theta \mathrm{M}]$. The rule (40), based on this last relation and on (53), enables to infer:

$$
\left(\mathrm{b}^{2} / \mathrm{c}, \mathrm{b}\right) \in \mathrm{Cl}[\mathrm{M}(2 \Theta \mathrm{M})]
$$

Multiplying (54) by $\mathrm{c} / \mathrm{b}$, we conclude that:

$$
(\mathrm{b}, \mathrm{c}) \in \mathrm{Cl}[\mathrm{M}(2 \Theta \mathrm{M})]
$$

The relations (55) and (52) can lead to an incoherence in the system. Indeed the level cuts of the fuzzy numbers $M$ and $\mathrm{M}(2 \Theta \mathrm{M})$ are of the form $[1-\varepsilon, 1 /(1-\varepsilon)]$ and $[1-2 \varepsilon$, $(1+\varepsilon) /(1-\varepsilon)]$ respectively, with $\varepsilon \in[0,1 / 3]$. The inequalities $1-2 \varepsilon \geq 2 / 3$ and $(1+\varepsilon) /(1-\varepsilon) \leq 3 / 2$ hold for $\varepsilon \in$ $[0,1 / 6] \subseteq[0,1 / 3]$, which signifies that the support of the fuzzy number $\mathrm{M}(2 \Theta \mathrm{M})$ is included in $[2 / 3,3 / 2]$. Thus, the initial system is incoherent according to the corollary.

Example 2: (Inspired form [1] and [10])

Now, let us consider a practical problem from the domain of acid-base chemistry. An important task in this domain is to find the concentration of $\mathrm{H}^{+}$in a solution. The concentration of ions in solution depends on the dynamic equilibrium resulting from competing chemical reactions. Consider dissolving an acid, $\mathrm{AH}$, in water. The two reversible reactions that occur, corresponding to the ionization of $\mathrm{AH}$ and $\mathrm{H}_{2} \mathrm{O}$, are given by (see [10] for more details):

$$
\begin{array}{cc}
\mathrm{AH} & \mathrm{H}^{+}+\mathrm{A}^{-} \\
\mathrm{H}_{2} \mathrm{O} & \mathrm{H}^{+}+\mathrm{OH}^{-}
\end{array}
$$

The equilibrium concentrations of the three ions $\left(\mathrm{H}^{+}\right.$, $\mathrm{OH}^{-}, \mathrm{A}^{-}$) and the acid (AH) are determined by the following equations:

Charge balance: $\left[\mathrm{H}^{+}\right]=\left[\mathrm{A}^{-}\right]+\left[\mathrm{OH}^{-}\right]$
Mass balance: $\quad \mathrm{C}_{\mathrm{a}}=\left[\mathrm{A}^{-}\right]+[\mathrm{AH}]$

Acid ionization equilibrium: $\mathrm{K}_{\mathrm{a}}[\mathrm{AH}]=\left[\mathrm{A}^{-}\right]\left[\mathrm{H}^{+}\right]$

Water ionization equilibrium: $\mathrm{K}_{\mathrm{w}}=\left[\mathrm{OH}^{-}\right]\left[\mathrm{H}^{+}\right]$

Square brackets denote concentrations; $C_{a}=10^{-5}$ is the initial concentration of the acid; $K_{w}=10^{-14}$ is the ion product of water; and $\mathrm{K}_{\mathrm{a}}=10^{-2}$ is the ionization constant of the acid.

It has been pointed out in [1][10][11] that solving this set of equations analytically for $\left[\mathrm{H}^{+}\right]$results in a cubic equation which is difficult to solve. An alternative to this approach is to use the qualitative reasoning based on the fuzzy relations of closeness $(\mathrm{Cl})$ and negligibility $(\mathrm{Ne})$. For example, a chemist might guess that the acid is strong, so that $\left[\mathrm{OH}^{-}\right]$and $[\mathrm{AH}]$ is negligible w.r.t. [A] (these assumptions can be used in simplifying and solving equations (56) to (59)). Now, assume that a chemist makes the following assumptions:

$$
\begin{aligned}
& \left(\left[\mathrm{OH}^{-}\right],\left[\mathrm{A}^{-}\right]\right) \in \mathrm{Cl}[\mathrm{M}] \\
& \left([\mathrm{AH}],\left[\mathrm{A}^{-}\right]\right) \in \mathrm{Cl}[\mathrm{M}]
\end{aligned}
$$

Now, the system to solve is formed of equations (56) to (61). Relation (58) implies that $\mathrm{K}_{\mathrm{a}} /\left[\mathrm{H}^{+}\right]=\left[\mathrm{A}^{-}\right] /[\mathrm{AH}]$. 
Which signifies that the pairs $\left(\left[\mathrm{H}^{+}\right], \mathrm{K}_{\mathrm{a}}\right)$ and $\left([\mathrm{AH}],\left[\mathrm{A}^{-}\right]\right)$ satisfy the same relation. Thus,

$$
\left(\left[\mathrm{H}^{+}\right], \mathrm{K}_{\mathrm{a}}\right) \in \mathrm{Cl}[\mathrm{M}]
$$

The chaining of the rules (8) and (25), applied on (60) and (61), enables to conclude that:

$$
\left(\left[\mathrm{OH}^{-}\right],[\mathrm{AH}]\right) \in \mathrm{Cl}\left[\mathrm{M}^{2}\right]
$$

The rule (7) applied on (63), enables to obtain $\left([\mathrm{OH}]+\left[\mathrm{A}^{-}\right],[\mathrm{AH}]+\left[\mathrm{A}^{-}\right]\right) \in \mathrm{Cl}\left[\mathrm{M}^{2}\right]$. It implies that:

$$
\left(\left[\mathrm{H}^{+}\right], \mathrm{C}_{\mathrm{a}}\right) \in \mathrm{Cl}\left[\mathrm{M}^{2}\right]
$$

according to (56) and (57). The relation (62), since $\mathrm{Cl}[\mathrm{M}]$ $\subseteq \mathrm{Cl}\left[\mathrm{M}^{2}\right]$, implies that:

$$
\left(\left[\mathrm{H}^{+}\right], \mathrm{K}_{\mathrm{a}}\right) \in \mathrm{Cl}\left[\mathrm{M}^{2}\right]
$$

Thus, the concentration $\left[\mathrm{H}^{+}\right]$is close to $10^{-5}$ and $10^{-2}$ (in the sense of the fuzzy set $\mathrm{M}^{2}$ ), according to (64) and (65). This is impossible in the chemical context. Therefore, the set of equations (56) to (61) is incoherent. This situation can be explained by the fact that the assumptions (60) and (61) that a chemist has made, are unjustified. So, these assumptions can not be used for simplifying equations (56) to $(59)$ in order to compare $\left[\mathrm{H}^{+}\right],\left[\mathrm{OH}^{-}\right],\left[\mathrm{A}^{-}\right]$, and $[\mathrm{AH}]$ between them or with the order of magnitude of exogenous quantities like $\mathrm{C}_{\mathrm{a}}, \mathrm{K}_{\mathrm{a}}$, and $\mathrm{K}_{\mathrm{w}}$. Although, a chemist can make other assumptions in order to solve equations (56) to (59). For instance, the assumptions $\left(\left[\mathrm{OH}^{-}\right],\left[\mathrm{A}^{-}\right]\right) \in \mathrm{Ne}[\mathrm{M}]$ and $\left([\mathrm{AH}],\left[\mathrm{A}^{-}\right]\right) \in \mathrm{Ne}[\mathrm{M}]$, can be justified, and so lead to the solution of eqns (56) to (59).

\section{CONCLUSION}

Symmetric variants of inference rules have been proposed. Such variants provide less precise results than possible; but they make symbolic reasoning on the fuzzy relations of closeness and negligibility simple and efficient in practice. We can chain all the new rules without caution and yet guarantee the validity of the inferred relations. We have shown that this type of reasoning can be used as a tool for detecting the incoherence of a set of equations, and for justifying the order of magnitude assumptions that scientists and engineers make in simplifying and solving equations. One of our immediate future works is to implement a systematic tool for testing the coherence.

\section{References}

[1] Bennett S.W. Approximation in mathematical domains. In proceedings of the tenth International Joint Conference on Artificial Intelligence, Los Altos, CA, 1987, pp. 239-241.

[2] Dubois D., Prade H. Fuzzy numbers : An overview. In : Analysis of Fuzzy Information, Vol. 1: Mathematics and Logic (J.C Bezd., ed.), CRC Press, BocaRaton, FL., 1987, pp. 3-39.
[3] Dubois D., Prade H. Fuzzy arithmetic in qualitative reasoning. In: Modeling and control of systems (A Blaqui re Editor), Lecture Notes In Control and Information Sciences, 121, Springer-Verlag, 1988, pp. 457-467.

[4] Dubois D., Prade H. Order of magnitude reasoning with fuzzy relations. Revue d'Intelligence Artificielle (herm s, Paris) 3(4), 1989, pp. 69-94.

[5] Dubois D., Hadj-Ali A., Prade H. Raisonnement sur des ordres de grandeurs relatifs avec des relations flouesQuelques nouveaux $r$ sultats. In: Actes de la $7 \mathrm{me}$ Conf rence sur la Logique Floue et ses Applications (LFA), Lyon, 3-4 December, 1997, pp. 253-260.

[6] Dubois D., Prade H., Ughetto L. Checking the coherence and redundancy of fuzzy knowledge bases. IEEE Trans. on Fuzzy Systems, Vol. 4, No. 3, August 1997, pp. 398-417.

[7] Hadj-Ali A., Dubois D., Prade H. Raisonnement sur les ordres de grandeurs relatifs avec des relations floues, appliqu aux probabilit s qualitatives. In: Proc. 8th French Conf. On Fuzzy Logic \& Appl. (LFA), Rennes, November, 1998, pp. 229-234.

[8 ] Kuipers B. Qualitative Reasoning - Modeling and Simulation with Incomplete Knowledge. The MIT Press, Cambridge, MA, 1994.

[9] MQ\&D Project (Dague P., Ed.). Qualitative reasoning: a survey of techniques and applications. AICom, The Eur. J. on Artificial Intelligence, 8, 1995, pp. 119-192.

[10] Nayak, P.P. Order of Magnitude Reasoning using Logarithms. In proceedings of the Knowledge Reasoning Conference (KR 92), Cambridge, Octobre 25-29, 1992, pp. 201-210.

[11] Raiman O. Order of magnitude reasoning. Proc. of AAAI Conference, Philadelphia, August, 1986, pp. 100104. Extended version: Artificial Intelligence, 51, 1991, pp. 11-38.

[12] Zadeh L.A. A theory of approximate reasoning. In : Machine intelligence, Vol. 9 (J.E. Hayes, D. Michie, L.I. Mikulich, eds), Elsevier, N.Y., 1979, pp. 149-194. 